\title{
Los rituales del espacio público en la configuración del régimen franquista. Estudio del Congreso Eucarístico de Bilbao, 1944
}

\author{
The rituals of the public space in the configuration of Franco's regime. \\ Study of the Eucharistic Congress of Bilbao, 1944
}

\author{
Maialen ALtunA ETXEBERRIA \\ Universidad del País Vasco- Euskal Herriko Unibertsitatea
}

\begin{abstract}
RESUMEN
El objetivo de este artículo es ahondar en el análisis de la construcción simbólica del franquismo poniendo la atención en el Congreso Eucarístico de Bilbao de 1944. El interés se centra en identificar los elementos plásticos, sensoriales y teatrales que se utilizaban en estos rituales y con ello se pretende ahondar más en el estudio de los elementos no discursivos que operaban en el control social y la imposición del orden social franquista.

El foco del análisis se centra en los momentos rituales en los que se ocupaban las calles de la ciudad y profundiza también en su significado. Por un lado, la misa y procesión destinada a niños y niñas se vincula al intento de crear una impronta emocional y afectar a las subjetividades de los que se consideraban el futuro de la nación. Por el otro, la procesión final en la que estaban llamados a participar activamente únicamente los hombres pudo ser útil para representar simbólicamente el papel que debía representar cada miembro de la sociedad en la nación franquista, reforzando para ello un modelo de masculinidad paternalista de corte carlista que fue ganando protagonismo en el régimen por su potencial para conseguir el orden social en la posguerra.
\end{abstract}

PALABRAs CLAVE

Congresos Eucarísticos; espacio urbano; ritual colectivo; control social; franquismo.

\section{ABSTRACT}

The aim of this article is to delve into the analysis of the symbolic construction of the Franco regime, paying attention to the Eucharistic Congress of Bilbao in 1944. The interest is focused on identifying the plastic, sensory and theatrical elements that were used in these rituals. Doing so it is intended to delve further into the study of the non-discursive elements that operated in the social control and the imposition of the Francoist social order.

The analysis focuses on the ritual moments in which the streets of the city were occupied and also delves into their meaning. On the one hand, the mass and procession for boys and girls is linked to the attempt to create an emotional imprint and affect the subjectivities of those who were considered the future of the nation. On the other hand, the final procession in which only men were called to participate actively could be useful to symbolically represent the role that each member of society should play in the Francoist nation, reinforcing a Carlist-style model of paternalistic masculinity that was gaining prominence in the regime due to its potential to achieve social order in the postwar period.

\section{KEYWORDS}

Eucharistic Congresses; urban space; collective rituals; social control; Francoism. 
El objetivo de este texto es proponer un análisis de la sociedad de posguerra desde el análisis de rituales político-religiosos del espacio urbano. Para ello, el estudio se centrará en los rituales de los Congresos Eucarísticos, unos congresos de carácter público que se celebraban en espacios urbanos de diversas ciudades del mundo y que tuvieron una amplia presencia en el contexto vasco de la posguerra. El análisis de estos espacios públicos ritualizados está enfocado a ahondar en el estudio de los mecanismos de control social de carácter simbólico que operaron en la implantación de la dictadura en los contextos urbanos.

Concretamente, nos centraremos en el Congreso Eucarístico de carácter provincial que se celebró en Bilbao en el año 1944, y dentro de este congreso analizaremos detalladamente dos momentos rituales: la misa y procesión de los niños y la procesión final. Se han seleccionado estos actos porque fueron estos rituales los que ocuparon las calles de la ciudad en una demostración de fuerza y porque, significativamente, estaban destinados a dos segmentos concretos de la sociedad: a los niños y niñas, por un lado; y a los hombres, por otro. Son significativos los protagonistas del evento, ya que los primeros constituían el futuro de la nación y los segundos formaban la base de la jerarquía paternalista que se quería reforzar.

Las fuentes que se utilizarán para este trabajo son las crónicas y fotografías del evento y los discursos en él pronunciados, junto con obras teóricas producidas por la Iglesia. En el análisis se pondrá especial énfasis en la espacialidad del ritual y en el uso de los elementos no discursivos.

\section{Congresos Eucarísticos. Rituales de masas urbanos}

Los Congresos Eucarísticos son rituales que se celebran en el espacio público, sobre todo de las grandes ciudades ${ }^{1}$, y que se remontan a la Francia de la segunda mitad del siglo XIX, en un contexto en el que las posiciones anticlericales de parte de la sociedad se hicieron patentes. Estas posiciones anticlericales se fueron haciendo fuertes en las ciudades europeas e incluían la prohibición de realizar actos rituales religiosos en los espacios públicos ${ }^{2}$. Esta pugna por la presencia del catolicismo en las naciones modernas tuvo un desarrollo complejo y extenso en el tiempo. Contrariamente a otros países, en el caso español este conflicto no se consiguió resolver y esto contribuyó a una prolongada guerra cultural intermitente, con períodos de intensidad variable en los que la pugna por el espacio público fue un elemento principal ${ }^{3}$.

En España, una recuperación de la Iglesia en el siglo XIX tuvo como contrapartida una reacción anticlerical a principios del siglo XX. En este caso, además, el debate no se limitó a la necesidad de secularización del Estado, sino que se abrió a la necesidad de laicización de la sociedad misma y se incrementó el debate sobre el papel

1. Desde un primer momento, los congresos tuvieron una vocación internacional, ya que se entendía que la Iglesia católica se enfrentaba a un problema común y global, un cambio internacional que afectaba a las bases mismas de la concepción de la sociedad.

2. Natalia NúÑEZ, “'La Reconquista de nuestro territorio cristiano’. Espacio urbano y religión en el Congreso Eucarístico Internacional de Madrid, 1911”, Itinerantes. Revista de Historia y Religión, 8 (2018), p. 44.

3. Francisco Javier RAMÓn SolAns, “'El catolicismo tiene masas’. Nación, política y movilización en España, 1868-1931”, Historia Contemporánea, 51 (2015), p. 432 (https://doi.org/10.1387/hc.14716). 
de la Iglesia en la escuela y de su presencia en el espacio público. En este momento histórico, por primera vez la Iglesia se percató de que estaba perdiendo el control de un terreno que hasta entonces había estado bajo su dominio: la calle.

Los católicos tuvieron una reacción activa ante estos cambios y para ello utilizaron los medios modernos de movilización de masas; por ello, el catolicismo adaptó sus prácticas para que tuvieran una presencia multitudinaria en las calles ${ }^{4}$. En el caso español, estas celebraciones se convirtieron en parte del patrimonio místico católico, que el régimen utilizó para afianzarse ${ }^{5}$. Siguiendo lo señalado por Ismael Saz, la religión católica se impuso, pero en una forma extrema de "politización de la religión" 6 . El congreso analizado en este artículo es uno de los actos modernos y novedosos de masas que se organizaron en este contexto, con el añadido interés de ser un ritual colectivo que tuvo lugar en un momento crucial de la dictadura, en el que la presencia de los elementos fascistas empezaba a decaer después de la derrota de la ofensiva fascista de principios de los años cuarenta. Además, este congreso se sitúa en plena reorganización del régimen, que a partir de 1943, al preverse la derrota del Eje en Europa, se va resituando cada vez más en la línea nacionalcatólica ${ }^{7}$. Debido a esta situación, la búsqueda de legitimidad se fue centrando cada vez más en el catolicismo, como se hizo patente en la crisis gubernamental de 1945, cuando dio comienzo el colaboracionismo católico con el régimen propiamente dicho ${ }^{8}$.

Para entender la posición que representaban los Congresos Eucarísticos en la posguerra, es necesario recordar que la crisis entre el régimen republicano y la jerarquía eclesiástica empezó con la aprobación de la Constitución de 1931. En ella se hacía efectivo el primer intento de “desconfesionalización y secularización del Estado"9. La Guerra Civil se presentó como parte de la recristianización que sería imprescindible para la regeneración nacional la cual, a su vez, significaba la instauración de un orden antimoderno ${ }^{10}$. De esta manera, la condena a la República se relacionaba con la pérdida de los valores tradicionales y de una visión de la realidad atravesada por el catolicismo. Específicamente, el debilitamiento de estos valores se relacionaba con la decadencia de los actos litúrgicos y la distorsión de su sentido ${ }^{11}$.

Por ello, el régimen dio mucha importancia a los actos públicos encaminados a restaurar aquel orden social que se basaba en una manera concreta de entender la sociedad y las relaciones sociales. En el plano institucional, este hecho se pudo observar

4. Ibídem.

5. Aurora MorcILlo, En cuerpo y alma. Ser mujer en tiempos de Franco, Madrid, Siglo XXI, 2000, p. 34.

6. Ismael SAZ, Las caras del franquismo, Granada, Comares, 2013, pp. 85-88.

7. Enzo Traverso, “Interpretar el fascismo. Notas sobre George L. Mosse, Zeev Sternhell y Emilio Gentile”, Ayer, 60 (2005), p. 252.

8. Javier TUSELl, Franco y los católicos. La política interior española entre 1945 y 1957, Madrid, Alianza, 1984, p. 36.

9. Giuliana Di FEBO, La santa de la raza. Un culto barroco en la España franquista, Barcelona, Icaria, 1988, p. 23.

10. Giuliana Di FeBo, “La Cuna, La Cruz y la Bandera. Primer franquismo y modelos de género”, en Isabel MoRANT (coord.), Historia de las mujeres en España y América Latina. Volumen IV. Del siglo XX a los umbrales del XXI, Madrid, Cátedra, 2008, p. 217.

11. Isidro Gomá y Tomás, El valor educativo de la liturgia católica, Barcelona, Rafael Casulleras, 1940, p. 102. 
en la utilización de elementos sagrados en la legitimación e implantación del Nuevo Estado. A medida que el ejército iba ocupando nuevos territorios, aparte de imponer una dura represión institucional, económica y social, también se implantaron diversas celebraciones litúrgicas solemnes que tenían como fin educar en los valores que era necesario acatar en la dictadura. Asimismo, estos actos tenían la intención de lograr el consenso social mediante la utilización del patrimonio cultural en beneficio del régimen que se quería instaurar ${ }^{12}$. Como explica Mary Vincent, el catolicismo fue esencial para la legitimación del régimen y así mismo jugaron un papel crucial las liturgias públicas que demostraban la unión entre el régimen, la nación y el catolicismo. Mediante estas representaciones de la tradición y la jerarquía acordes al franquismo se lograba que la asociación entre las comunidades jerárquicas religiosas y civiles fuera absoluta y, además, se conseguía que la comunidad local se inscribiera dentro de la nacional ${ }^{13}$. La intención es seguir la senda abierta por estos trabajos que han ahondado en la construcción simbólica del franquismo ${ }^{14}$, pero poniendo el énfasis principal en el análisis de un espacio ritual concreto y en el uso de los elementos emocionales y sensoriales.

Es importante recordar que varios sectores de la sociedad se identificaban con algunos de los valores que defendía la dictadura, como el orden, la religión y la tradición ${ }^{15}$, de forma que se lograba la identificación con aspectos del imaginario colectivo de grupos heterogéneos ${ }^{16} \mathrm{y}$ no solamente con la oligarquía tradicional que había perdido poder con los cambios sociales y políticos acaecidos con la llegada de la modernidad. Por todo ello, como afirma Claudio Hernández, el proyecto de renacionalización y recatolización no vino impuesto solamente desde el Estado ya que "considerables sectores sociales se implicaron directamente, dieron su aprobación o transigieron con proyectos que, para ellos, suponían la (re)ordenación del mundo en consonancia con su visión" ${ }^{17}$. Por lo tanto, aunque se debe afirmar que el catolicismo de la posguerra no fue monolítico desde el punto de vista político y sea necesario tener en cuenta las graves tensiones internas dentro de los sectores agrupados en el régimen ${ }^{18}$, la defensa de una base católica ortodoxa constituyó el principal punto de unión de los sectores implicados en el gobierno dictatorial ${ }^{19}$.

12. Di FeBo, La santa de la raza, p. 29-31.

13 Mary VinCENT, “La paz de Franco: el concepto de jerarquía en la España de la posguerra” en Carolyn P. BOYD (ed.), Religión y política en la España contemporánea, Madrid, Centro de Estudios Políticos y Constitucionales, 2007, p. 94.

14. El trabajo más destacable en este sentido: Zira Box, España, Año Cero. La construcción simbólica del franquismo, Madrid, Alianza, 2010.

15. Antonio Cazorla, La consolidación del Nuevo Estado franquista (1938-1953), Madrid, Marcial Pons, 2000, p. 203.

16. Francisco Coвo Romero y Teresa María Ortega López, Franquismo y posguerra en Andalucía Oriental. Represión, castigo a los vencidos y apoyos sociales al régimen franquista, 1936-1950, Granada, Universidad de Granada, 2005, p. 406.

17. Claudio HERnÁNDEZ BURGOS, Franquismo a ras de suelo. Zonas grises, apoyos sociales y actitudes durante la dictadura (1936-1976), Granada, Universidad de Granada, 2013, p. 109.

18. TuSELL, Franco y los católicos. p. 23.

19. Frances Lannon, Privilegio, persecución y profecía. La Iglesia Católica en España 1875-1975, Madrid, Alianza, 1990, pp. 262-263. 
En este contexto hay que situar los ritos y las manifestaciones litúrgicas que se acrecentaron durante la guerra y en los años posteriores y que llegarían a constituirse en parte integrante de esa "religiosidad total" que llevaría a una completa identificación entre valores, normas, costumbres y catolicismo ${ }^{20}$. La institución eclesiástica contaba con grandes infraestructuras para el control social y la movilización y, además, se beneficiaba de la gran ventaja de estar difundiendo unos mensajes que ya tenían un fuerte arraigo en la comunidad, por lo que poseía las herramientas óptimas para mantener la conformidad hacia el régimen, como afirma Ángela Cenarro “dejarle un espacio propio fue, sin duda, uno de los grandes logros de Franco en la empresa de obtener el consenso de la población”"21.

Así, lo sagrado se orientaba también a satisfacer exigencias políticas a través de un proceso de readaptación en clave ideológica del patrimonio simbólico tradicional. Para ello, se vuelve a modelos devocionales barrocos basados en la "fascinación de los fieles a través de lo externo, de la emotividad y de lo grandioso" 22 . Siguiendo a Clifford Geertz, los símbolos sagrados tienen "la función de sintetizar el ethos de un pueblo [...] y su cosmovisión, el cuadro que ese pueblo se forja de cómo son las cosas en la realidad, sus ideas más abarcativas acerca del orden" ${ }^{23}$. Los rituales colectivos como los aquí analizados son parte de esa readaptación de la religión en claves políticas y son, a su vez, parte de un estilo político nuevo propio de la modernidad. Para este nuevo estilo, los ritos y las liturgias jugaban un papel crucial y "constituían un elemento capital de una teoría política que no dependía del atractivo de la letra escrita" 24 , ya que ese discurso formaba parte de un ritual en el que lo que verdaderamente primaba era el entorno y las ceremonias que los rodeaban. Por ello, lo artístico y lo estético resultaba esencial para conseguir la unidad del símbolo ${ }^{25}$.

En el Nuevo Estado, la celebración de solemnes ceremonias litúrgicas fue una de las formas encaminadas a conseguir el consenso social. Se establecieron unos rituales católicos de una fuerte tradición que, como ritos colectivos, constituían un intento de crear y mantener una determinada cultura, una determinada serie de supuestos mediante los cuales se controla la experiencia. Así, los ritos representaban la forma de las relaciones sociales y al darle a estas relaciones expresión visible permitían que la gente conociese su propia sociedad. Los ritos actuarían sobre el cuerpo político mediante el instrumento simbólico del cuerpo físico ${ }^{26}$.

\section{Congreso Eucarístico de Bilbao y subjetividades nacionalcatólicas}

El primer Congreso Eucarístico de Bilbao estuvo precedido por el I Congreso Eucarístico de Álava, que se celebró en Vitoria del 21 al 25 de octubre de 1942. El

20. Di FeBO, La santa de la raza, pp. 32-33.

21. Ángela CenARro, “Élites, Partido, Iglesia. El régimen franquista en Aragón, 1936-1945”, Studia histórica. Historia contemporánea, 13-14 (1995-1996), p. 100.

22. Di FEBO, La santa de la raza, pp. 32-33.

23. Clifford GeerTZ, La interpretación de las culturas, Barcelona, Gedisa, 2003, p. 89.

24. George L. Mosse, La nacionalización de las masas, Madrid, Marcial Pons, 2005, p. 24.

25. Ibídem, p. 23.

26. Mary Douglas, Pureza y peligro. Un análisis de los conceptos de contaminación y tabú, Madrid, Siglo XXI, 1991, p. 150. 
mismo día de la clausura de este evento se acordó celebrar el próximo Congreso Eucarístico con carácter provincial en 1944 en Bilbao. Después, sería el momento de Gipuzkoa, con la celebración de su Congreso Eucarístico provincial en Donostia-San Sebastián del 25 de mayo al 2 de junio de $1946^{27}$.

El evento estaba formado por diversas actividades. El estudio se centrará en algunas de ellas, las que se realizaban ocupando el espacio público. Estos rituales estaban dirigidos a dos de los fragmentos de la población: los niños y niñas y los hombres. Por un lado, la presencia de los niños en el espacio público estaba dirigido a garantizar la permanencia del régimen, y para ello se quería inscribir en el cuerpo de aquellos un vínculo con ciertos valores. Por otro lado, el otro gran ritual que ocupó las calles fue el de la clausura, que estaba dirigida, significativamente, a los hombres. En este ritual se buscaba, por un lado, una vinculación entre la masculinidad, la religiosidad activa y la ciudad moderna, y por otro, se representaba el orden social y la posición de cada uno de los miembros de la sociedad, reforzando la masculinidad paternalista que estaba en la base de esta concepción de sociedad. Los futuros miembros debían incorporar los valores que lo sustentaban y los protagonistas actuales debían interiorizar la posición que en ella tenían.

Cada día del congreso eucarístico estaba dedicada a diferentes colectivos y tenía diversas actividades programadas. Los primeros días del congreso, del 13 al 16 de mayo, estuvieron destinados a actividades generales, como charlas y representaciones teatrales, todos ellos en torno a la temática de la eucaristía y se celebraron en espacios cerrados como teatros. El día 17 de mayo dio comienzo el congreso con diversos actos institucionales ${ }^{28}$ y siguió con días temáticos: jueves 18, Día del Niño; viernes 19, Día del Sacerdote y de las Juventudes; sábado 20, Día del Magisterio y de las Señoras ${ }^{29}$. El día 21, domingo, estuvo destinado a la clausura del evento; fue el día más ceremonial y se centró en la participación de los hombres.

Estas jornadas tenían, por una parte, un objetivo educativo y divulgativo, que se realizaba mediante discursos y conferencias dirigidas a diferentes sectores de la sociedad, además de varias representaciones artísticas de carácter divulgativo, como charlas líricas, representaciones teatrales o cánticos. Por último, se celebraban algunos rituales colectivos en el espacio público. Todos ellos estaban relacionados con la

27. Aparte de estos Congresos Eucarísticos de carácter provincial, también se organizaron congresos de carácter más específico en diferentes pueblos importantes de las provincias vascas. La profusión de estos rituales en estos años de la posguerra nos muestra que se consideraron adecuados en el proceso de construcción del nuevo régimen. También se puede observar que a partir de los años 1950 la cantidad de los Congresos Eucarísticos disminuye, sobre todo los más locales, aunque perduraron los congresos internacionales y nacionales.

28. La celebración de la apertura empezó con la reunión de las autoridades en el Ayuntamiento de Bilbao, para dirigirse desde allí a la Basílica del Señor Santiago, donde tras el discurso del obispo de la diócesis tomaron la palabra el presidente de la Diputación y el alcalde de Bilbao. Después, el presidente de las Cortes Españolas, Esteban Bilbao, en sustitución y representación del Caudillo, leyó su discurso.

29. Los días asignados a grupos, del 18 al 20, tenían diversas actividades programadas y destinadas especialmente a estos colectivos, pero también aparecían en el programa otros colectivos. Por ejemplo, el día 18 la misa de las siete de la mañana estuvo dirigida específicamente a las “muchachas de servicio”. El mismo día a las 12.30 se celebró una misa ofrecida a los obreros, el viernes una dedicada a los sacerdotes y religiosos y el 20 a los maestros por la mañana, y a los directivos y gerentes de las empresas por la tarde. También se celebraron misas en diferentes iglesias y parroquias de la ciudad; en ellas se trataba una misma temática, dirigida específicamente a los miembros de la sociedad divididos en hombres, mujeres, chicas y chicos jóvenes. 
temática de la eucaristía, pero la forma de divulgar o educar sobre la idea base de la doctrina católica era diversa.

El elemento emocional utilizado en estos Congresos tenía relevancia en la configuración misma de los discursos. Se buscaba que estos impactaran en los oyentes. Las autoridades del Régimen y de la Iglesia eran conscientes del poder que representaba la utilización de las actividades religiosas como medio para la educación, para que la sociedad se organizara y entendiera a sí misma dentro de lo establecido desde la doctrina católica y desde el Régimen. La base de esta posición era la cruzada contra la "racionalidad", que la Iglesia y el Estado consideraban la mayor enfermedad de la modernidad $^{30}$, contraponiendo la fe y la obediencia como elementos supremos frente a una racionalidad moderna. En este mismo congreso, así expresaba estas ideas en su discurso Esteban Bilbao, el representante del Caudillo en el evento:

\begin{abstract}
La nueva filosofía, harta de peregrinar por el espacio de un idealismo absurdo, de hundirse en la ciénaga de un apestoso materialismo, convicta de su impotencia, después de interrogar a todas las escuelas con la pregunta escéptica de Platón "Qué es la verdad?”, acaba por refugiarse, como último asidero de su desconsolada y agnóstica razón, en este otro misterio no menos insondable de la vida: Pero, ¿qué es la vida? ¿Átomo o idea; mecanismo biológico, como pretende Descartes y hoy repiten otras escuelas? ¿compilación de fuerzas físico-químicas, como explican la escuela y el sistema materialista? [...].

Y mientras filósofos rinden culto a la vida queriendo personificar en ella la realidad de un poder misterioso rival de la Divinidad, señor del mundo entero, en el inmenso campo de batalla que ocupa una gran parte del Planeta perecen a millones pueblos enteros, vidas sin cuento, que el genio del mal ofrenda insaciable al imperio de la muerte. [Grandes aplausos] ¡Qué distinta y qué grande es, en cambio, la vida a la luz de la Teología cristiana! Dios, en su infinita sabiduría, quiso juntar las tres vidas -vegetativa, sensitiva y racional- en la humana criatura, convirtiendo al hombre en un microcosmos síntesis del Universo entero ${ }^{31}$
\end{abstract}

Este tipo de arengas, lanzadas en el espacio público a los miles y miles de personas congregadas, y los diversos discursos emitidos en espacios cerrados $\mathrm{y}$ dirigidos a un público más específico tenían como objetivo explicar las razones por las cuales era necesario seguir las pautas sociales marcadas. Como se puede ver en este fragmento, el propósito principal de los discursos y los rituales que se acrecentaron en la posguerra era defender la vuelta a la visión ontológica del catolicismo tradicional.

Los mandatarios católicos tenían claro que el designio de recatolizar la sociedad y parar las nuevas visiones que ponían en entredicho toda la estructura social anterior, no podía llevarse a cabo solamente mediante un intento discursivo y racional de proselitismo. Según los eruditos católicos, el medio superior para la difusión del catolicismo eran los actos pragmáticos y entre ellos uno de los principales era la utilización de la liturgia. Como explica este artículo de la revista Ecclesia:

\footnotetext{
La Liturgia es, en primer lugar, la forma social del culto católico; es decir, la forma oficial y pública de expresión, de apostolado y de eficacia popular de la religión cristiana; y, por lo mismo, es el más poderoso instrumento de popularización de la fuerza entrañable del Catolicismo. [...] Ella es "toda para todos”, y no reconoce más aristocracia que la del nivel de entendimiento y corazón de aquellos que la practican. Por la Liturgia se verifica esta nivelación mental que es característica del pensar de las muchedumbres, dando al mismo tiempo pan de idea, de fuerza, de arte, de sentimiento y
}

30. Antonio Cazorla, Fear and progress: ordinary lives in Franco's Spain, 1939-1975, Chichester, Wiley-Blackwell, 2009, p. 91.

31. “Congreso Eucarístico de Vizcaya”, Boletín Oficial del Obispado de Vitoria, 1-7-1944, pp. 321-322. 
de esperanza a todo el pueblo. La Liturgia utilizó siempre, de un modo vasto y continuo, los métodos pedagógicos más aptos para la democratización de todo lo que puede levantar a las muchedumbres. Éstas se mueven generalmente por sugestión, por imaginación, por sentimiento; y nuestra Liturgia ha popularizado lo más alto y divino, condensándolo en frases, fórmulas, símbolos, ritos, gestos, indumentarias y arte, haciendo que el pueblo conviviese con todo ello para que paulatinamente se transformara el alma de las multitudes ${ }^{32}$.

Siguiendo estas ideas, lo que más interesa en este análisis son las formas de educar o convencer que estaban relacionadas con esos elementos plásticos, teatrales, simbólicos y sensitivos característicos de la liturgia, esto es, al situarnos en el espacio público se quiere observar lo que no fue meramente discursivo, sino que incidía en los aspectos teatrales y sensoriales. Concretamente, en esta propuesta se realizará un análisis de dos actos principales de este congreso que tuvieron lugar en el espacio público: por un lado, la misa y la comunión general del día del niño y; por otro, las procesiones de los días de los niños y del día de clausura del congreso.

\title{
Liturgia y eucaristía. La regeneración de la nación desde la raíz
}

Como se ha expuesto anteriormente, el primero de los actos rituales dentro del congreso que ocupaba el espacio público fue el Día de los Niños. En realidad, fueron dos los actos principales que tuvieron lugar este día: la comunión general de los niños y, una procesión que recorrió las vías más importantes de esta ciudad.

Como se podrá ver en la narración del evento, la organización del ritual estaba destinada a influir en los participantes de manera emocional y sensitiva. Se recalcó la importancia de la participación de los niños y niñas en estas actividades, ya que se afirmaba la idea de que estas vivencias tan emocionales se quedarían grabadas en su memoria y serían transmitidos incluso a su descendencia:

\begin{abstract}
teniendo muy presente la gran influencia que en la vida futura habría de ejercer en el niño el recuerdo de esta fiesta [...] jamás podrán olvidarse, por largos años que vivan, todos los que en ella tomaron parte y que, si hoy son la mejor esperanza de nuestro pueblo, dentro de unos años, constituirán los futuros hogares de Vizcaya, en la gran familia de España ${ }^{33}$.
\end{abstract}

Por ello, la organización de esta actividad tenía como objetivo ofrecer una vivencia que incorporara ciertos valores básicos del régimen y así contribuyera a la creación de subjetividades afines en las futuras generaciones. Para ello, la ritualidad pautada estuvo dirigida a crear una honda impronta que marcara a estos niños y niñas, lo que se realizó mediante actos simbólicos como la eucaristía colectiva y mediante el despliegue de recursos destinados a crear una atmósfera que ayudara a crear un ambiente sensorial y emocional propicio para que dichos actos quedaran anclados en su memoria.

Para este Día del Niño, que tuvo lugar el jueves 18, estaban convocados niños y niñas de toda la provincia de Bizkaia. Según la narración del congreso, desde primera hora de la mañana las calles de la villa fueron inundándose de niños y niñas, que

32. GomÁ, El valor educativo de la liturgia católica, pp. 234-235.

33. Crónica del Congreso Eucarístico de Vizcaya, [s. l., s. e., s. f.], p. 68. 
llegaban mediante líneas férreas y demás medios de transporte acompañados de maestros, sacerdotes, consiliarios de asociaciones religiosas o directores de catequesis ${ }^{34}$.

El primer elemento reseñable del evento es que el espacio público aparecía transformado para este evento multitudinario. Las vías principales de la ciudad, que en la vida habitual eran utilizadas para el tránsito de ciudadanos y transportes y para fines comerciales, se encontraban completamente cambiadas para que ese mismo espacio estuviera en sintonía con la grandeza del evento religioso. Esto se puede apreciar mejor en la alocución del prelado realizada en el Congreso. Se hacía referencia a la transformación del espacio público urbano en un espacio místico y religioso, puesto que, en esos días, como dice el prelado, la ciudad se transformaba en un lugar santo:

\begin{abstract}
Amadísimos hijos míos. Rebosen nuestras almas de júbilo y entusiasmo porque durante los días de nuestro Congreso Eucarístico, la emprendedora y laboriosa villa de Bilbao se va a transformar, en cierto modo, en una Jerusalén celestial. [...] Y durante nuestro Congreso, amadísimos míos, podemos decir que no habrá templo en Bilbao, no; porque la villa entera se convertirá en un vasto y grandioso trono de amor ${ }^{35}$
\end{abstract}

La ciudad se presentaba como transformada en un templo, en un espacio sagrado. También se hacía referencia a la participación de las personas en estos actos, ya que se llamaba a todos los habitantes de la ciudad a participar activamente en él, cada uno en los actos y posiciones marcados. Para que las normas de cómo se debía participar estuvieran claras, las pautas eran ampliamente difundidas por las diferentes congregaciones que se ocupaban de su organización.

Imagen 1: Imagen de la Misa celebrada en el Día de los Niños en la Plaza Moyúa

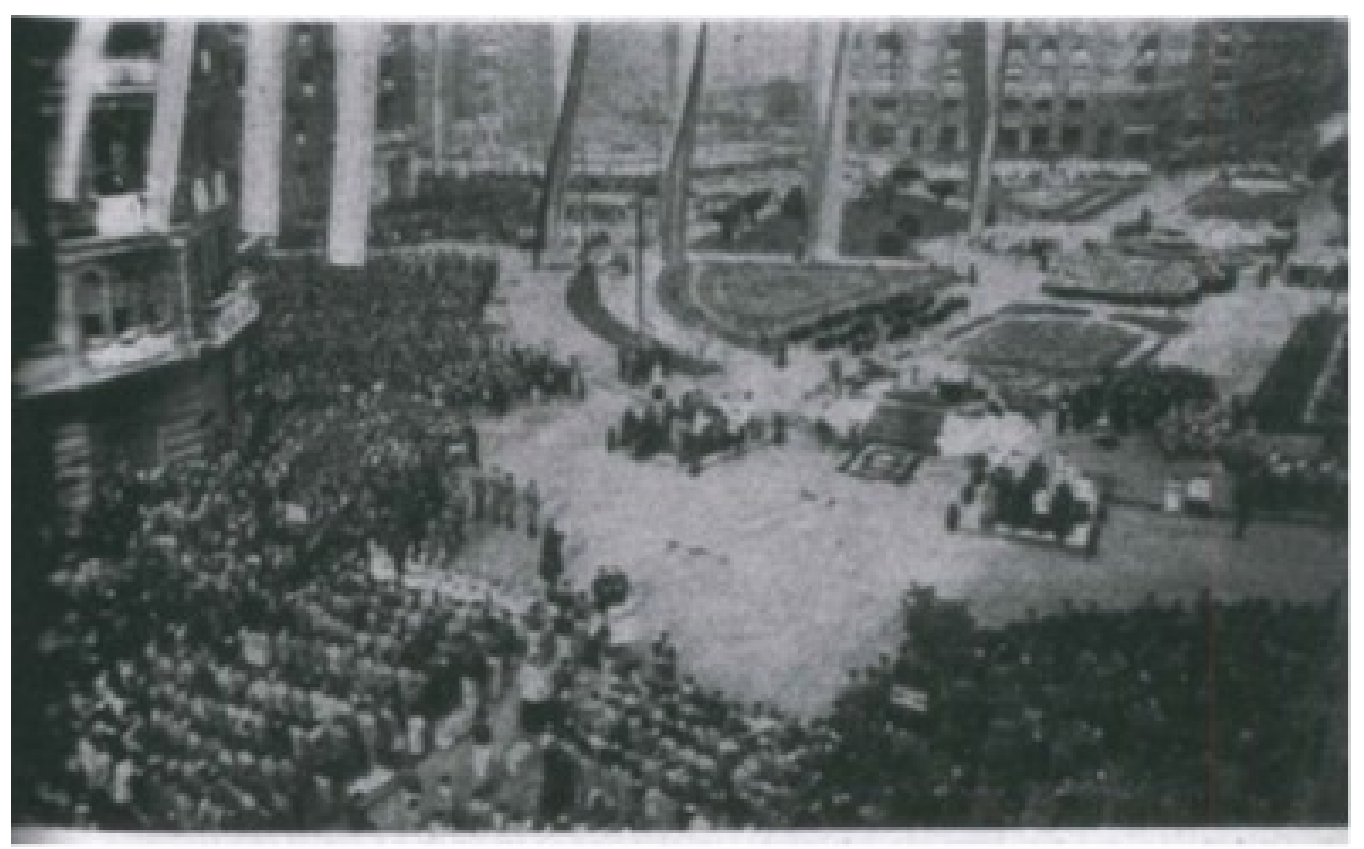

F.: "De la Comunión infantil: Los Cruzados eucarísticos en la plaza Moyúa”, Boletín Oficial del Obispado de Vitoria (BOOV), 1-7-1944.

Para que la transformación del espacio urbano en un espacio místico se hiciera palpable, el espacio se transmutaba utilizando diversas estrategias. Los lugares principales de los rituales se engalanaban con símbolos, banderas y flores.

34. Ibídem.

35. “Congreso Eucarístico de Vizcaya”, pp. 316-317. 
Todas las casas estaban con colgaduras y guirnaldas, que daban un bello aspecto a la edificación. Frente a la calle se levantaba el altar de elegante sencillez, engalanados con flores. En la plaza estaban colocados los estandartes y banderas de todos los Colegios y Escuelas de Vizcaya. Dando guardia a los altares se situaron los Cruzados con sus vistosos trajes. Todo contribuía a dar brillantez, a dar encantos a aquel cuadro magnífico, de una insuperable grandiosidad ${ }^{36}$.

Toda esta trasformación estaba encaminada a conseguir la exaltación de los sentidos que es necesario para que la Liturgia impregne mediante la conexión con los sentidos. La visión, el olfato y la audición formaban parte de esta instrumentalización. La institución católica era consciente de la importancia del discurso, pero también de las vivencias colectivas ritualizadas que ayudaban a la interiorización de los mensajes. Como afirmaba el cardenal Isidro Gomá y Tomás, era imprescindible que las ideas llegaran a tomar vida para conseguir el fin que pretendían: determinar las subjetividades. De esta manera lo expresaba en su libro El valor educativo de la liturgia católica:

El punto inicial de la formación religiosa es la idea, y, tratándose de la formación cristiana, es la fe: "La fe que viene por el oído, el oído atento a la palabra de Dios". [...] Pero la idea se traduce en "vida”, y ésta, a su vez, propaga y agranda la idea. [...] porque la idea, cuando es "vivida", adquiere matices que pueden darle mayor eficacia y fuerza persuasiva que cuando sólo es "hablada" 37

Se consideraba que la mejor forma de hacer "vivir" las ideas era mediante las experiencias de la liturgia católica. Estas experiencias religiosas tendrían un poder sugestivo del que eran perfectamente conocedores y que se explotaba para conseguir acciones concretas. En este fragmento del antes citado trabajo de Isidro Gomá, se puede ver hasta qué punto tenían trabajado incluso teóricamente las funciones que podían conseguir estas experiencias.

A este poder objetivo de la representación litúrgica del Ideal, hay que añadir el valor sugestivo de la Liturgia en orden al mayor conocimiento del Ideal-Jesus. [...] ...no puede negarse al simple hecho de la experiencia religiosa, tal como se produce en el ejercicio de nuestra Liturgia, un poder coercitivo que agrupa todo elemento de orden intelectual, volitivo y de emoción alrededor de una idea capital, para comunicarle mayor luz y relieve. Todo está trabado y se conjuga armónicamente en este maravilloso mecanismo del ser humano; tratándose de la experiencia religiosa, parece hay como una convergencia de las fuerzas psíquico-emotivas en el sentido de lo divino, tan profundo en el hombre ${ }^{38}$.

Es interesante esta última reflexión, porque como el texto dice "estos elementos sensoriales pueden dar a la idea una mayor eficacia en orden a la acción”, esto es, estaban destinados a influir en la acción. Por lo tanto, se considera que el objetivo de la institución eclesiástica sería utilizar esos mecanismos para crear las subjetividades que conformarían la sociedad nacionalcatólica. Como afirmaba el mismo cardenal Gomá, "la Liturgia es un elemento generador y conservador de la verdad y un método para uniformar el pensamiento de las multitudes ${ }^{39}$.

Para verlo en un acontecimiento concreto, seguiremos con la crónica de cómo se sucedió el ritual de la mañana. El ritual de la comunión tuvo lugar a las nueve y media

36. Ibídem, p. 334.

37. GOMÁ, El valor educativo de la liturgia católica, p. 102.

38. Ibídem, p. 179.

39. Ibídem, p. 243. 
de la mañana en la Plaza Moyúa de Bilbao, transformada para este congreso. En ella se instalaron ocho altares, cada uno de ellos dirigido a una de las calles que acceden a dicha plaza. Los miles de niños estaban distribuidos en estas calles de forma anteriormente pactada y ordenada, de manera que todos tenían acceso visual al altar correspondiente. Los niños de Bilbao se colocaron a lo largo de la Gran Vía, arteria principal de la ciudad, en dirección a la Diputación. Las niñas de los colegios religiosos se situaron en la plaza y en la Gran Vía en dirección al Sagrado Corazón. Los niños y niñas de los pueblos, en cambio, se situaron de forma separada, pero agrupados por arciprestazgos.

Estos ocho altares estaban adornados con miles de flores naturales y a su alrededor se encontraban niños con trajes de Cruzados Eucarísticos. El vestido de Cruzado estaba formado por un uniforme de seda blanca con una cruz roja al pecho y se completaba con una lanza.

Imagen 2: Cruzados Eucarísticos en la Plaza Moyúa durante la Comunión infantil

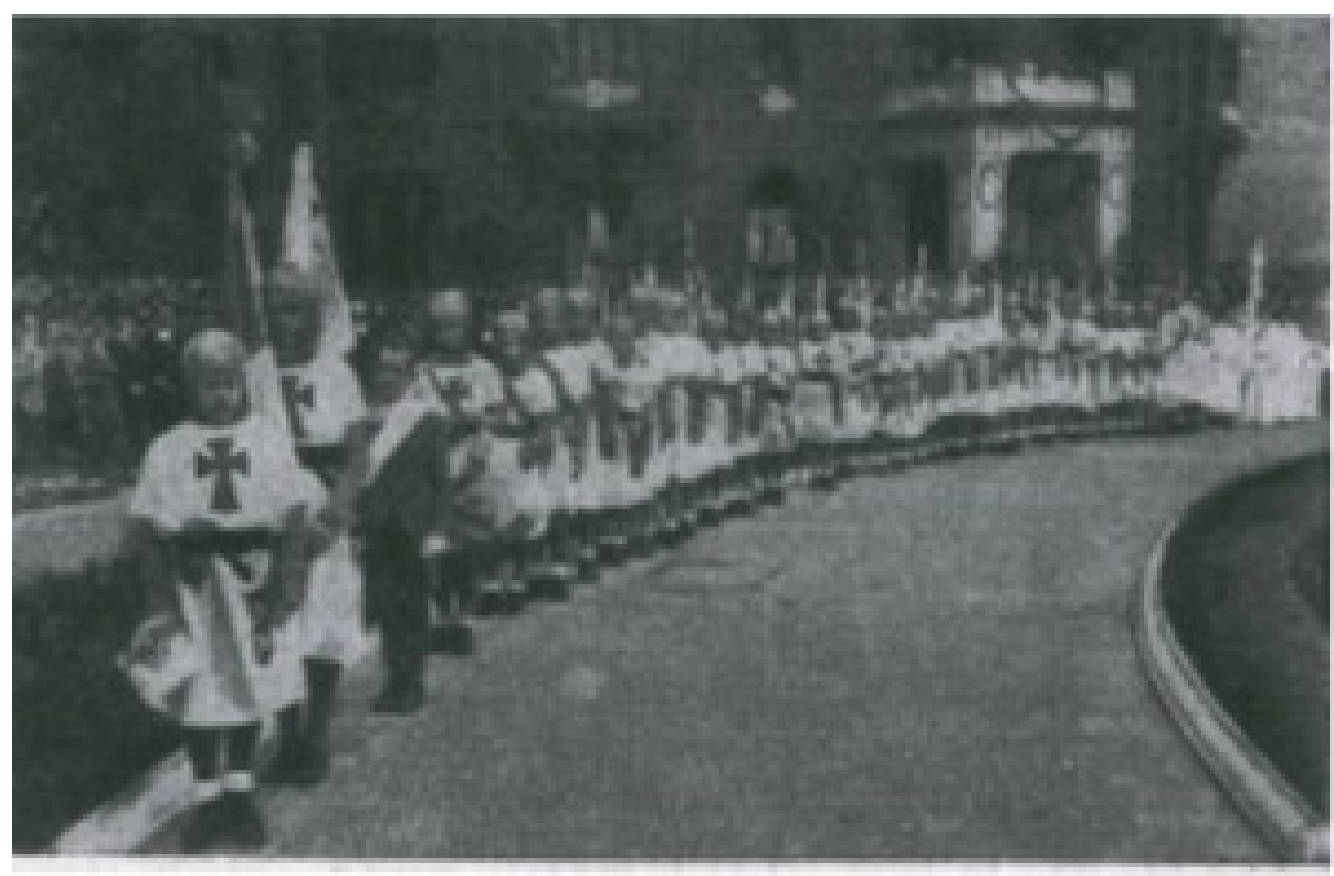

F.: “De la Comunión infantil: Los Cruzados eucarísticos en la plaza de Moyúa”, BOOV, 1-7-1944.

Esta indumentaria que utilizaron los niños varones se repitió en diversos rituales públicos que se celebraron durante el Congreso y tenía como objetico proteger a la Hostia Sagrada. Delante del altar principal, el que daba a la Gran Vía hacia la Diputación, se colocaron unos reclinatorios destinados a las autoridades: gobernador civil, alcalde y jefe provincial del Movimiento.

El acto ritual principal, el de la misa, empezó al unísono en los ocho altares, y gracias al gran despliegue técnico de altavoces los niños podían seguir la misa desde todos los lugares. En esta misa pública, uno de los actos principales fue el del alzar, que se realizó junto con la interpretación del Himno Nacional ejecutada por la banda musical. Después, todos los asistentes cantaron al unísono el Himno Eucarístico para, a continuación, proceder a la comunión colectiva. Los altavoces se utilizaron una vez más para guiar a los niños y niñas allí reunidos. Siguiendo una organización previa, se acercaron a los ocho altares ciento cuarenta y dos sacerdotes para, entre todos, poder dar comunión a los miles de niños y niñas en apenas una hora. Según los cálculos estimados por los organizadores, los niños y niñas que tomaron comunión fueron 54.000. 
Seguidamente, se procedió al acto de consagración de los niños de Bizkaia al inmaculado corazón de María, que se realizó mediante la lectura de uno de los niños en representación de todos. Después, por petición del Papa se procedió a la petición de paz en el mundo. Para terminar los actos, todos los asistentes se arrodillaron para recibir la bendición por parte del prelado de la diócesis. Terminado este acto, las autoridades desfilaron ante el obispo para besar su anillo, y así lo hicieron también algunos de los niños asistentes ${ }^{40}$.

Por la tarde tuvo lugar el otro gran ritual público del día, la procesión infantil. Según los cálculos de los organizadores, participaron en torno a 52.000 niños y niñas. Muchos de ellos iban vestidos de cruzados y acólitos, y los demás con trajes de fiesta, muchos de ellos a su vez con banderas. La procesión duró unas dos horas, durante las cuales se entonaron diferentes cánticos, organizados por los grandes altavoces situados durante el recorrido, al tiempo que se rezaba el rosario ${ }^{41}$. En este y otros momentos ya nombrados se puede ver la importancia que se daba al aspecto sonoro en toda esta ritualidad, desde la organización e inversión que requería el despliegue técnico para que los altavoces abarcaran todo el espacio utilizado en el ritual a la trascendental participación de las bandas de música en los momentos culminantes de la celebración.

Imagen 3: Procesión infantil a su paso por una de las calles principales de Bilbao.

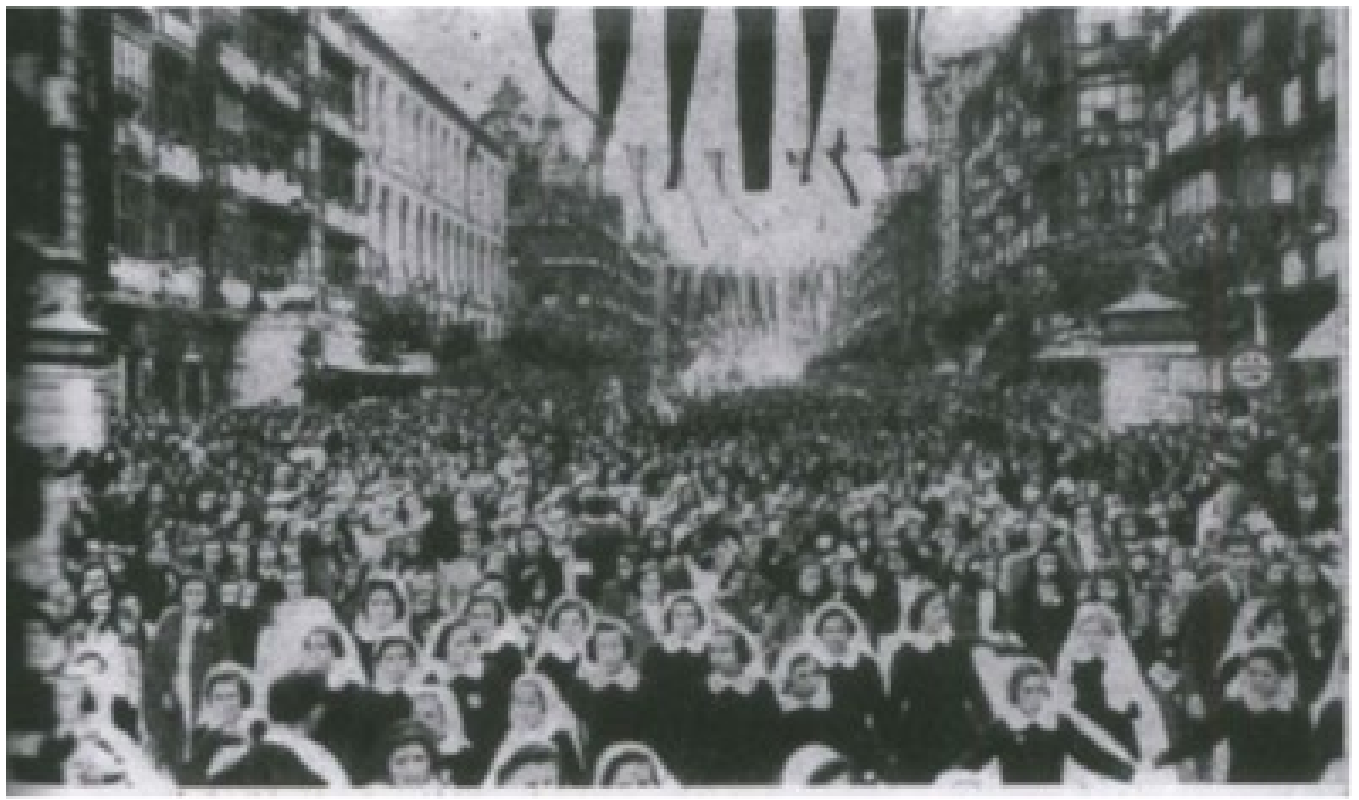

F.: “La procesión infantil: un detalle”, BOOV, 1-7-1944.

Con anterioridad al ritual, se buscó la participación de los músicos locales para que produjeran canciones propias para el evento, siempre dirigidas a la temática principal: la eucarística. También es destacable que las canciones fueron ensayadas por los niños en las escuelas o centros religiosos a los que acudían y que se hiciera difusión de las letras de las canciones tanto por los medios de comunicación como por la difusión de libretos en el mismo momento. Entre las composiciones musicales que tuvieron protagonismo en estos actos es importante destacar que en los momentos álgidos era el Himno Nacional el que sonaba, como se verá durante la narración de los diferentes actos rituales. La otra música principal fue la canción del Congreso 
Eucarístico, que fue entonada en momentos clave del ritual que aparecen en la narración.

Por lo tanto, como sucede en muchos rituales colectivos, la música tuvo un papel principal en el transcurso de los eventos. Se lograba una sonoridad diferente con la participación de varias bandas de música y con la disposición de múltiples altavoces para que los discursos y los cánticos se expandieran por el espacio urbano. Esta referencia del congreso de Bilbao puede ilustrar algunas de estas transformaciones que tenían lugar estos días y su gran impacto emotivo:

\begin{abstract}
Miles de gargantas, como los ancianos de la visión de San Juan, van a cantar con emoción al Cordero de Dios, conmoviendo los ecos de esta villa con las notas de los himnos litúrgicos, densos de conceptos sublimes y de encendidos amores eucarísticos ${ }^{42}$. Encontraban en aquel gran coro de frescas gargantas una sonoridad brillante y conmovedora, y ponían en nuestras calles y plazas una nota de vida y de color, ¿̇a quién que los contemplara y oyera no se le grabaron en el corazón, para no olvidarlos mientras viva? ${ }^{43}$
\end{abstract}

Por otra parte, la temporalidad y espacialidad del ritual estaban totalmente pautadas y se recorrían los espacios más significativos y los lugares de la ciudad más importantes simbólicamente. La procesión salió a las tres del mediodía desde la misma Plaza Moyúa hacia la Gran Vía. Alrededor de las calles, en las ventanas y miradores asistían miles de espectadores y los edificios del recorrido estaban decorados con banderas y colgaduras nacionales y pontificias. Abrían la procesión los guardias municipales, a los que seguían carrozas artísticas con niñas disfrazadas de ángeles. Después desfilaba una sección ciclista y tres centurias del Frente de Juventudes con bandas de trompetas y tambores. Siguiendo a éstos, un abanderado con una gran enseña nacional. Detrás de él desfilaban, acompañados de sus maestros, los niños de Bilbao, muchos llevando sus trajes de comunión, y seguidamente las niñas. Tras ellos desfilaban los niños de los pueblos, agrupados por arciprestazgos.

Nos detenemos aquí para señalar la importancia de la presencia de las carrozas y su significado en toda esta ritualidad. Más allá de la representación de la jerarquía social en el espacio público, la intención de los congresos eucarísticos era también experimentar en el espacio público la cosmovisión en la que estaba basada la religión católica, y para conseguir esto tenía mucha importancia la utilización de elementos artísticos, tanto plásticos como teatrales y musicales. Uno de los elementos centrales de los congresos eucarísticos era reforzar la visión del catolicismo representando uno de sus actos fundacionales y elementos más importantes de su cosmovisión. Este elemento era el de la eucaristía y el hecho de que la Hostia Consagrada fuera Dios mismo. En un momento en el que esta visión basada en el dogma y la fe estaba en disputa constante e intermitente con una visión más materialista de la realidad, los congresos representaban un intento de que aquella perdurara también en las ciudades modernas, los lugares en que el materialismo estaba ganando más terreno. Por lo tanto, los congresos eucarísticos representaban un intento de ocupar el espacio urbano con el acto mayor que sintetizaba la ideología en la que se basaba la sociedad tradicional católica. Para ello, se sacaba al espacio público la Hostia Sagrada y se reivindicaba o recordaba que este objeto era Dios mismo.

42. “Congreso Eucarístico de Vizcaya”, Boletín Oficial del Obispado de Vitoria, 1 de julio de 1944, p. 317.

43. Crónica del Congreso Eucarístico de Vizcaya, p. 83. 
He aquí el Cordero de Dios, ese mismo Cordero, digo, lo vamos a ver pasar por las vetustas calles y por las nuevas y espaciosas vías de esta villa [...]. Teólogos profundos invocarán la indiscutible autoridad de las Sagradas Escrituras para desvanecer las ilusiones que se forjan los sentidos y para vencer las repugnancias de la razón para terminar enseguida con grito triunfador: ¡Ahí, en la Hostia, está Dios; creed, adoradle! ${ }^{44}$

Para ayudar a la expresión de ideas tan abstractas, delante de las procesiones desfilaban unas carrozas alegóricas diseñadas para representarlas. Las carrozas alegóricas tenían, pues, gran importancia, porque explicaban de una manera plástica las ideas principales en las que se basaba la doctrina católica.

Imagen 4: Dos detalles de las carrozas alegóricas que desfilaron en las procesiones.
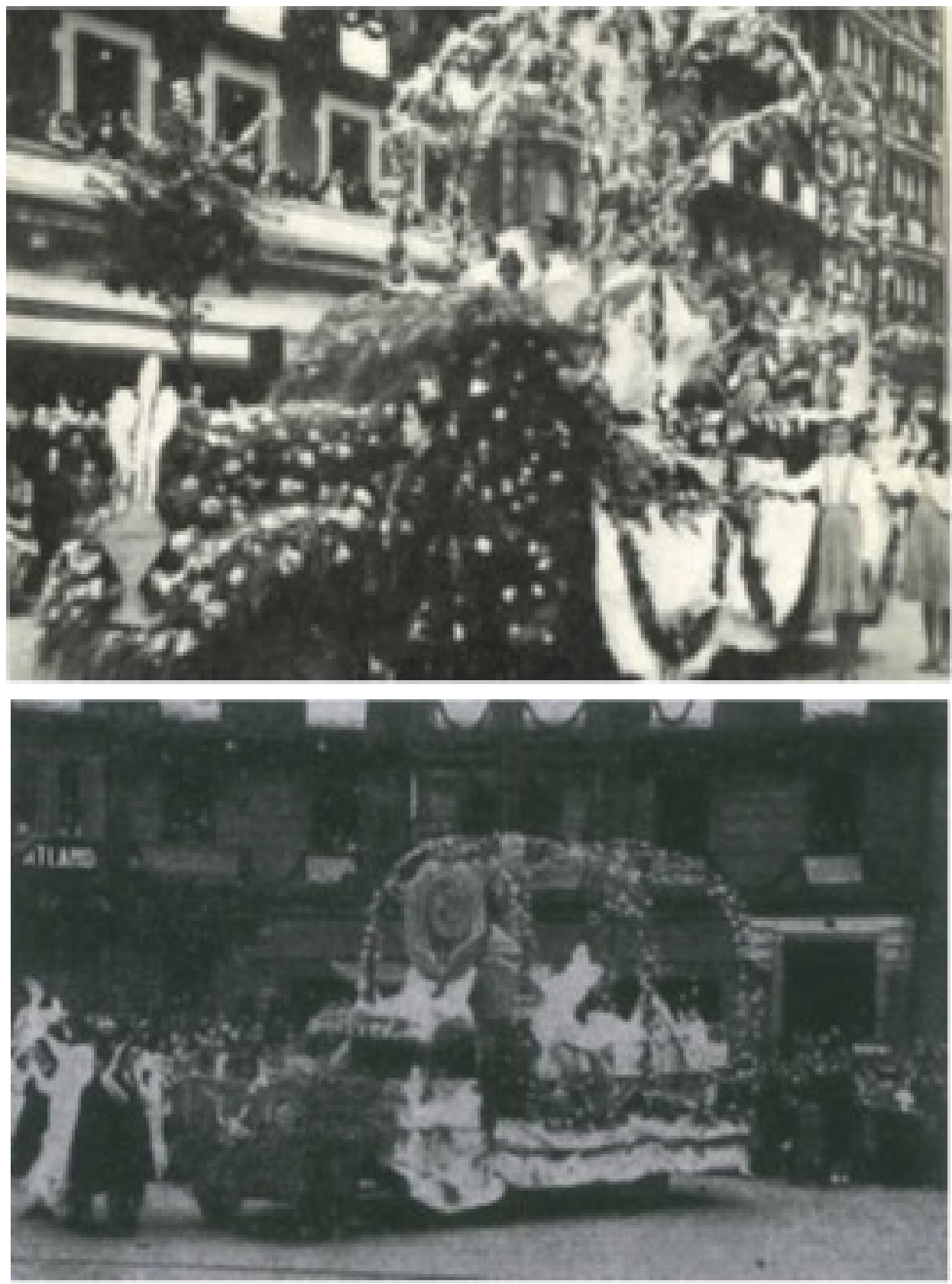

F.: Arriba: "Día del niño. Tres de las carrozas que figuraron en el desfile procesional", Crónica del Congreso Eucarístico, p. 73. Abajo: "Una de las carrozas que desfiló en la procesión”, BOOV, 1-7-1944.

44. “Congreso Eucarístico de Vizcaya”, Boletín Oficial del Obispado de Vitoria, 1-7-1944, p. 317. 
Es significativo que dichos elementos estuviesen inspirados en las representaciones que se hicieron populares en otro momento de la historia en el que la visión ontológica en la que se basaba el catolicismo se tambaleó y se estableció una fuerte réplica para reafirmarla: la Contrarreforma. Los congresos eucarísticos y los elementos que los constituyen están basados en los autos sacramentales que tuvieron una gran presencia durante los siglos XVI y XVII en España. De hecho, esos días se representaban varias obras de la época, como las de Calderón de la Barca. Estas referencias, así como la importancia que tenían en ese contexto, se pueden entender en las palabras del cardenal Gomá en una de sus obras teóricas sobre la eucaristía:

\begin{abstract}
Ojalá contribuyamos, con este esfuerzo, a despertar en el alma inmortal de nuestro pueblo su fe vieja y su amor, por nadie superado en el mundo, al adorable Sacramento del Altar. Porque España era grande, en los siglos XV-XVII, cuando la Eucaristía era el Sol que alumbraba los espíritus. Era entonces, cuando en los Autos sacramentales se popularizaba la teología del Sacramento, y el "pueblo teólogo" -que tal se requería para espectador de aquel género dramático- afinaba su pensamiento y su sensibilidad cristiana en aquellas ficciones poéticas en que supo Calderón encerrar el meollo de la teología eucarística, entre discretos escolásticos y aletazos de insuperado lirismo ${ }^{45}$.
\end{abstract}

En estos rituales la intención principal era educar a la sociedad en una visión de la realidad que estaba perdiendo terreno. Se trataba de explicar mediante la escenificación, los símbolos y los sentidos la cosmovisión en la que estaba basada la sociedad tradicional. Por ello, las referencias al Siglo de Oro eran frecuentes y las estrategias utilizadas para que la cultura nacionalcatólica se instaurara estaban vinculadas también a los elementos barrocos que se habían utilizado en el mismo Siglo de Oro. En este caso, la cultura de lo barroco se entiende, en palabras de Aurora Morcillo, como "un instrumento operativo, cuyo objeto es actuar sobre unos hombres de los cuales se posee una visión determinada, a fin de hacerlos comportarse, entre sí y respecto a la sociedad que conforman y al poder que en ella manda, de manera tal que se mantenga y potencien la capacidad de autoconservación de dichas sociedades, conforme aparecen estas estructuradas bajo los fuertes principios políticos del momento" ${ }^{46}$. Por ello, uno de los elementos que destacaban en estos congresos era su carácter integral y su gran plasticidad ${ }^{47}$. Esta es la razón por la cual elementos como las carrozas, los bailes, las canciones y la escenografía tomaban tanta importancia.

Siguiendo con la escena de aquella tarde del jueves 18 de mayo de 1944, a la llegada de la cabeza de la procesión a la Plaza de España, salió de la iglesia de los PP. Agustinos la Custodia. Era portada por sacerdotes y escoltada por cruzados, a ambos lados iban sacerdotes y religiosos y detrás el arcipreste y todos los párrocos de la ciudad. Tras ellos, el obispo presidiendo el acto, y como segunda presidencia se encontraban las autoridades y jerarquías del Movimiento. Cuando llegaron a la Plaza de Moyúa se interpretó el Himno Nacional. A continuación, se realizó el baile de San Miguel de Arrechinaga, típico de la zona, que representa el triunfo de San Miguel sobre

45. Isidro GOMÁ, La eucaristía y la vida cristiana, Barcelona, Rafael Casulleras, 1940, p. VIII.

46. MORCILlO, En cuerpo y alma, p. 39.

47. Natalia NúÑEZ, "De la coexistencia entre las naciones a la experiencia globalizada: el Congreso Eucarístico Internacional” en Damián GonzÁlez MADRIZ, Manuel OrTIZ HerAs, y Juan Sisinio PÉREz GARZÓn (coords.), La Historia, lost in translation? Actas del XIII Congreso de la Asociación de Historia Contemporánea, Cuenca, Ediciones de la Universidad de Castilla-La Mancha, 2017, p. 2.460. 
la Humanidad y el demonio. Este baile se representó en la Plaza Moyúa, en frente de la Diputación, en la Plaza de España y en el Arenal. En esta última plaza se encontraban a su vez las carrozas alegóricas que habían desfilado ${ }^{48}$.

Imagen 5: El grupo Artibay de Markina realizando una de sus actuaciones del baile de San Miguel San Miguel de Arrechinaga.

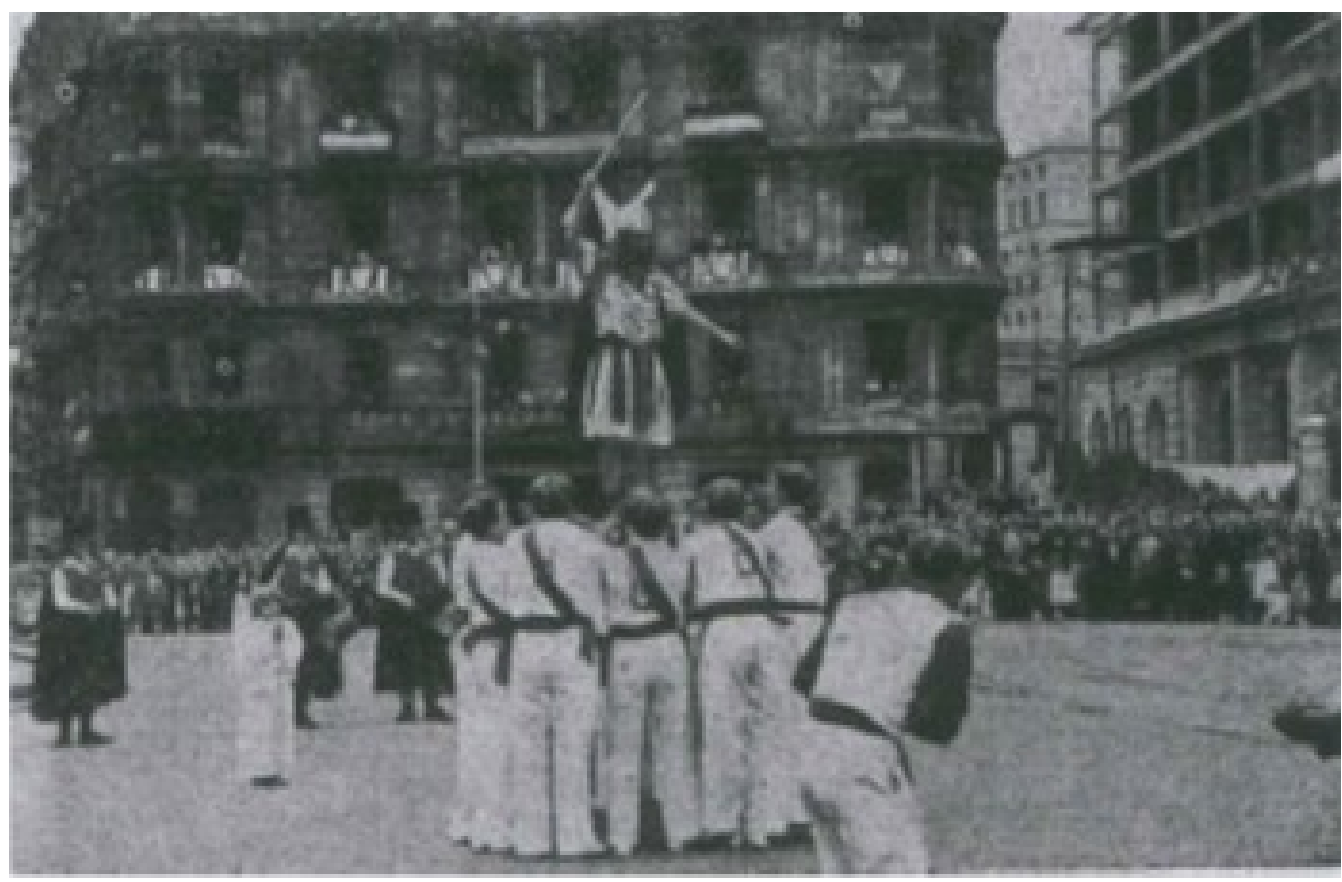

F.: "Los danzaris de Marquina, ante el Santísimo, en el baile de San Miguel de Arrechinaga”, BOOV, 17-1944.

La custodia llegó al Arenal pasadas las seis y media y se colocó en el enorme altar construido y adornado para el evento. Este último recorrido lo realizó por un pasillo abierto entre los niños y niñas, ya colocados según el orden preestablecido. Al colocar la Sagrada Forma en el altar sonó de nuevo el Himno Nacional y todos los asistentes, incluidos los eclesiásticos, las autoridades y el público, se arrodillaron. Seguidamente, se representó, por última vez, el baile de San Miguel de Arrechinaga y se entonó el Tantum ergo. El obispo procedió entonces a la bendición de los asistentes que continuaban arrodillados y, mientras tanto, se oyó otra vez el Himno Nacional. Para terminar, se cantó el Cantemos al Amor de los Amores y, con ello, se dio por finalizado el día de los niños.

\section{La restauración del orden patriarcal: la centralidad masculina del Régimen. Procesión final del Congreso}

El siguiente ritual que vamos a analizar es el acto principal del día de clausura, el domingo 21 de mayo. En este día se produjo, junto con las señaladas en el día de los niños, el ritual más significativo que ocupaba el espacio público y en este caso también se trataba de una procesión.

Este acto central tiene especial interés porque se trataba de una procesión en el que se recreaba de una forma ritual el orden y la jerarquía de la sociedad y se remarcaba

48. Crónica del Congreso Eucarístico de Vizcaya, p. 84. 
el papel que jugaba cada uno en este orden. El acto central recalcaba la ocupación activa de los hombres católicos en el espacio urbano, mientras que los niños y niñas y las mujeres ocupaban los espacios de los márgenes y observaban el acto desde las aceras y los balcones. Por otro lado, el papel del Estado y del ejército quedaban remarcados mediante su participación de forma ordenada jerárquicamente y siguiendo los preceptos del ritual católico. Por último, la virilidad del régimen quedaba subrayado con la presencia militar con que se cerraba el ritual.

Este aspecto era destacable en la intencionalidad de unir el espacio de las ciudades y el espacio público, con la espiritualidad y, especialmente, con una forma de entender la espiritualidad viril. Es importante remarcar que la reconstrucción de la nación y la tradición realizada en el nacionalcatolicismo estaba vertebrada en base al género $^{49}$. Por ello, en las construcciones mítico-simbólicas utilizadas para la configuración del régimen, las referencias al orden y jerarquía de género fueron principales y se conformaron en base al catolicismo, como afirma Giuliana di Febo, hay una "significativa correspondencia entre la recuperación de ritos, ceremonias arcaicas y la remodelación de las pautas femeninas y masculinas ${ }^{50}$.

La República, siguiendo las ideas de modernidad, trajo consigo un cambio significativo en las relaciones de poder entre hombres y mujeres y con ello la puesta en cuestión del poder masculino tradicional. Los actos simbólicos que llevaban a recuperar la autoridad de los hombres y de los valores unidos a la virilidad tenían una gran repercusión en la afirmación de los valores nacionalcatólicos. Siguiendo el trabajo de Mary Vincent, aunque en los años de la guerra la masculinidad corporativa fascista, horizontal y belicosa ganó fuerza, en la posguerra ese referente fue abandonado a favor a una masculinidad paternalista, vertical y de linaje, que tan importante había sido en el carlismo $^{51}$. Las jerarquías entre los sexos de los carlistas definieron así el orden social de la posguerra, ya que fue más funcional para establecer el orden y control social.

La masculinidad paternalista de corte carlista tenía un fuerte arraigo en la sociedad vasca, sobre todo en la rural, y pudo dotar al régimen de un modelo ideal para la posguerra ya que le permitía mantener el vínculo con la victoria militar y al mismo tiempo ofrecía un modelo de autoridad paternal que enfatizaba la idea de orden natural. Por lo tanto, el paternalismo fue una pieza clave en la construcción del acuerdo social y, por ello, el modelo masculino paternalista de corte carlista fue el que se fue extendiendo en estos años de posguerra ${ }^{52}$.

El ritual al que hace referencia este apartado se puede entender en el contexto de esa reafirmación del modelo de masculinidad paternalista, ya que se trataba de una representación simbólica y ritualizada de ese orden de base que cimentaría la sociedad franquista nacionalcatólica. Además, eran precisamente las ciudades los espacios donde más disidencias había experimentado la jerarquía de género, y donde las masculinidades y feminidades alternativas habían tenido más presencia, por lo que desplegar dicho

49. Aurora G. Morcillo, True Catholic Womanhood. Gender ideology in Franco's Spain, DeKalb, Northern Illinois University Press, 2000, p. 27.

50. Giuliana Di FEBo, “Nuevo Estado, nacionalcatolicismo y género”, en Gloria NiELFA CRISTÓBAL (ed.), Mujeres y hombres en la España franquista: Sociedad, economía, política, cultura, Madrid, Editorial Complutense, 2003, p. 20.

51. Mary VinCENT, “La reafirmación de la masculinidad en la cruzada franquista”, Cuadernos de Historia Contemporánea, 28 (2006), p. 135.

52. Ibídem, p. 151. 
ritual en una ciudad como Bilbao representaba parte del establecimiento del nacionacatolicismo.

Los participantes que estaban llamados a participar activamente en el ritual eran los hombres mayores de dieciséis años de toda la provincia. Por ello, durante la tarde miles de hombres provenientes de diversos pueblos se fueron agolpando alrededor de las vías principales de la ciudad. A ellos se unieron también hombres venidos de Araba y Gipuzkoa.

En este caso, la convocatoria para la Comunión General estaba destinada a todos los hombres, pero estaba programada para realizarse en todas las parroquias de la ciudad, no en la calle, como en el caso de los niños y niñas. Después de que los hombres acudieran a las iglesias aledañas a comulgar, a las diez y media de la mañana se celebró una Misa Pontifical en el monumento al Sagrado Corazón en dirección a la Gran Vía.

Imagen 6: El altar colocado en el monumento al Sagrado Corazón

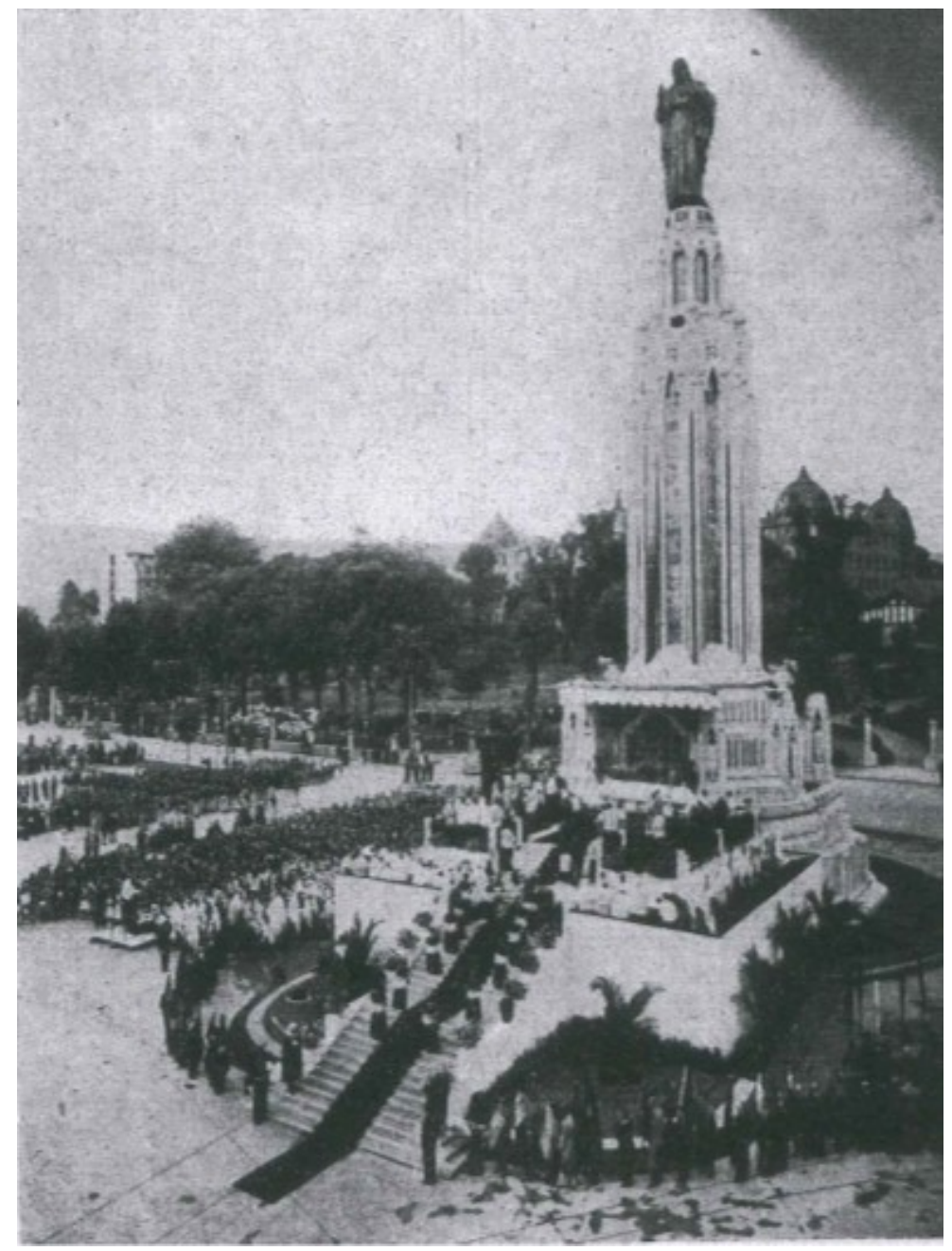

F.: "La Misa de Pontifical oficiada por el Nuncio de S. S. al pie del monumento al Sagrado Corazón de Jesús”, BOOV, 1-7-1944.

Para ello, se construyó un altar de dos pisos de dimensiones enormes al que se accedía por medio de unos cincuenta escalones. El altar estaba totalmente adornado con banderas y guirnaldas, flores y plantas naturales. Su primer piso estaba destinado al clero, mientras que en la parte superior se colocó un trono para el representante o nuncio del Papa y frente a él, tres espacios para los prelados, los cuales oficiaron la ceremonia. En una tribuna levantada en el propio altar superior, debía ocupar su lugar el presidente 
de las Cortes Españolas, Esteban Bilbao, en representación del Caudillo. Frente al altar se alzaba una tribuna destinada a las corporaciones provincial y municipal, y delante de estos los Ayuntamientos. En la misma plaza también tenían delimitado un espacio especial los representantes religiosos de Bilbao y provincia, las jerarquías del Movimiento, los representantes militares y los miembros directivos del Congreso.

En la Gran Vía y mirando al altar, se dispusieron miles de sillas para los congresistas, al tiempo que las aceras de alrededor se encontraban atestadas de gente que ocupaba el espacio que hay hasta la Plaza Moyúa. Por otro lado, en la Avenida de José Antonio se situaron el Frente de Juventudes y las fuerzas armadas y en la parte posterior de la plaza, la policía.

En este ritual en especial, se puede observar la importancia que se le daba a la ordenación espacial de los participantes del ritual, en el que cada participante tomaba la posición que correspondía a su lugar en la jerarquía social. Los actos estaban ordenados y dispuestos, de modo que cada participante encarnara el papel que le correspondía en el acto. Por lo tanto, la liturgia también era un medio destinado al establecimiento de la jerarquía y el control social.

Sin autoridad, no hay sociedad; Es su árbol maestro y el nervio de su acción. Hay relación íntima entre autoridad y religión: por ello la hay entre autoridad y culto. [...] La Liturgia, forma social del culto cristiano, debía infundir en las masas litúrgicas el alto sentido de autoridad que encierra nuestra religión divina. [...] Y como quiera que la Liturgia es función de jerarquía y pueblo, también éste debe entrar en la órbita de la autoridad y en el campo de la obediencia ${ }^{53}$.

Por la tarde vino el momento culminante del congreso, la procesión. El comienzo tuvo lugar en el Monumento del Sagrado Corazón con la llegada de las autoridades de Bizkaia: el Gobernador Civil a la cabeza, seguido de las jerarquías del Movimiento, jefes y oficiales del Ejército, Guardia Civil, fuerzas armadas y otras representaciones. Estos recibieron al Nuncio, al presidente de las Cortes Españolas y a los Prelados.

La procesión comenzó a las cuatro de la tarde. Primero salieron las carrozas alegóricas, seguidos de los guardias municipales y tamborileros del Ayuntamiento, alumnos de diversos colegios vestidos de Cruzados, después Centurias del Frente de Juventudes y tras ellos los fieles divididos por arciprestazgos, primero los de los pueblos. y cerrando, los bilbaínos. Tras ellos venía la Adoración nocturna, diferentes cofradías, la Junta Provincial y de Honor del Congreso, Símbolos de las basílicas y Cruces parroquiales, seminaristas, religiosos y sacerdotes y, por último, la carroza con el Santísimo y el Palio. Destacaba especialmente la marcialidad del acto, tanto en el orden mantenido por los asistentes, como en su posición jerárquica:

¡Qué orden y disciplina en las masas inmensas de hombres que fueron movilizados! ¡Qué grandiosidad y emoción reflejados en los rostros, muchas veces humedecidos por las lágrimas, de los que, desde balcones, ventanas, terrazas y aceras contemplaban el paso del Santísimo!

Las calles convirtiéndose, enseguida, en verdaderos ríos humanos y, para la hora señalada, hombres y jóvenes mayores de diez y seis años, los únicos que debían figurar en la procesión, se hallaban en la Avenida de José Antonio, ocupando el puesto que, por arciprestazgos, se les había señalado, para evitar confusiones ${ }^{54}$.

53. GoMÁ, El valor educativo de la liturgia católica, p. 231.

54. Crónica del Congreso Eucarístico de Vizcaya, p. 138-139. 
Un aspecto importante de esta procesión es la presencia de las fuerzas armadas. Todo el trayecto de la procesión estaba cubierto por ellas: en el Arenal y Calle Navarra, la Policía Armada, y desde Plaza España hasta la Gran Vía, soldados del regimiento de Garellano. La circunferencia de la Plaza Moyúa estaba rodeada de ametralladoras y la Plaza España, de la misma forma, de ametralladoras y morteros. Desde el final de la Gran vía hasta el Monumento del Sagrado Corazón, formaban los marinos con su armamento. Cerca del Monumento al Sagrado Corazón se situaron los miembros de una compañía de Infantería con banda de música. Además, tras el final de la procesión hubo un desfile militar por las mismas calles.

Siguiendo con la cabecera de la procesión, la custodia de oro fue llevada hasta la carroza, que estaba adornada con flores naturales, también mediante un solemne ritual. A la llegada del Santísimo sonó el Himno Nacional, y pasó por el arco formado por el grupo Artibay de Marquina antes de situarse en la carroza.

Para dar cuenta del tamaño del desfile, se explica que llegaban los primeros al Arenal cuando todavía quedaban hombres esperando a la salida, en la Avenida de José Antonio, un recorrido de unos dos kilómetros.

Imagen 7: Un momento de la procesión final del Congreso.

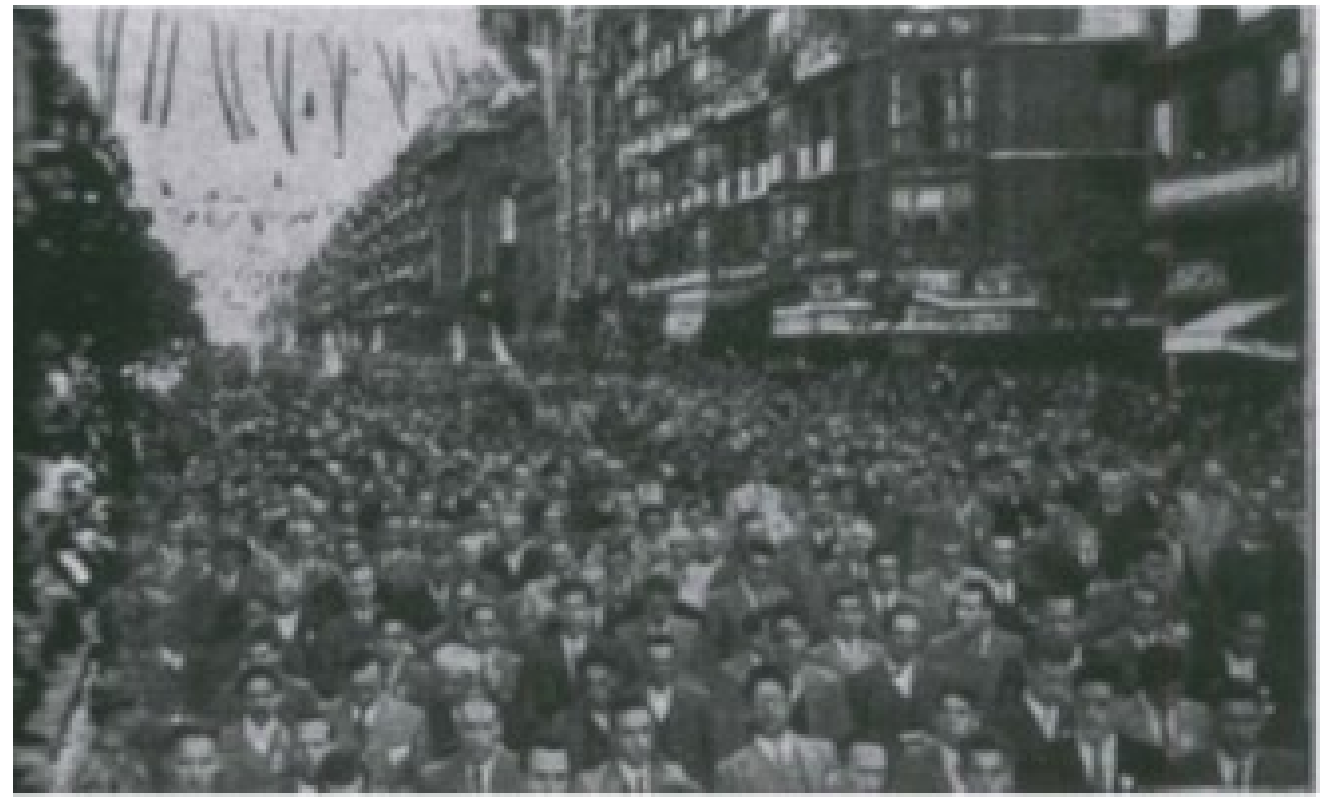

F.: “De la procesión final: La procesión eucarística a su paso por la Gran Vía”, BOOV, 1-7-1944.

Este acto de cierre del congreso, que fue el que más espacio ocupó en las crónicas, se presentaba como un acto de fuerza, como un recordatorio del poder de movilización que la Iglesia católica seguía teniendo, incluso entre los hombres y en las urbes más modernas e industriales. En este fragmento de la crónica del congreso se puede ver en qué términos se enfatizaba la ocupación de los hombres en masa de la ciudad moderna convertida en templo:

Entre tanto continuaba el desfile de los grupos de hombres concentrados en la Avenida de José Antonio y calles que desembocan en la misma. Las masas compactas de fieles desfilaban a todo lo ancho de las amplísimas calles del trayecto y sin dejar el menor espacio libre, entonando los Himnos del Congreso Eucarístico, que dirigían los coros desde los altavoces instalados en todo el recorrido. Era un desfilar incesante de una inmensa masa de hombres, cuyo número fue superior a los sesenta y cinco mil. [...] los 
grupos apretadísimos de hombres que cubrían toda la amplitud de las modernas avenidas del trayecto ${ }^{55}$.

De esta manera, la ritualización suponía una propuesta novedosa de entender el espacio público urbano, con la posibilidad de que también pudiera ser conceptualizado y vivido como un espacio espiritual ${ }^{56}$.

Cuando todos se incorporaron al desfile, a las cinco y veinte, salió la carroza que llevaba el Sacramento. Primero, recibió la oración del Nuncio y los prelados que, para ello, descendieron del altar. Después, el grupo Artibay realizó el baile y la carroza emprendió la marcha. Junto a la carroza iban el Nuncio y dos obispos y un auxiliar, seguidos por una bandera nacional; después, el presidente de las Cortes Españolas en representación del Caudillo, y seguidamente una presidencia formada por el gobernador civil y jefe provincial del Movimiento, el gobernador militar y otros mandatarios. A esta presidencia seguía el Ayuntamiento de Bilbao y la Diputación de Vizcaya. Tras ellos, venían jefes y oficiales de los Ejércitos de Tierra, Mar y Aire y los cuerpos de la Guardia Civil y la Policía Armada. Les seguían los delegados de Servicios de Falange Española Tradicionalista y de las JONS y otras jerarquías del Movimiento. Tras la representación de los Ayuntamientos de Bizkaia, cerraba la marcha la banda musical. Aparte de esta banda de música, participaron también las bandas municipales de Bilbao y algunas de los pueblos colindantes. A su vez, esperaban al comienzo de la procesión el grupo Artibay de Marquina que, al igual que en la procesión del Día del Niño, sería el responsable de realizar el baile de San Miguel de Arrechinaga.

Durante la procesión fueron repetidos diversos cánticos, para lo que se distribuyeron libretas con las letras. Desde los altavoces, se informaba del número de la canción que se iba a cantar a continuación, animando a los miles de participantes a hacerlo a viva voz y todos juntos. A estos cánticos se unían las mujeres y niños que contemplaban la procesión desde aceras y balcones. Las bandas acompañaban con su música la interpretación.

La próxima parada se realizó frente al Colegio del Sagrado Corazón de la Gran Vía a donde habían sido trasladados unos trescientos enfermos para recibir la bendición del Nuncio. Después de esta parada, la carroza con el sacramento llegó al Arenal. Allí se había levantado un enorme altar, decorado con flores y plantas naturales de varios colores. Para la llegada, el Arenal estaba rebosante, con miles de personas y, según los cronistas del evento, se vivieron momentos de gran emoción.

\begin{abstract}
Y allí, en la ancha acera del Arenal, entre la policromía de ornamentos sacerdotales y banderas eucarísticas; de macetas y de las flores más variadas; de sotanas negras y encarnadas becas cruzadas sobre los pechos de los seminaristas y de uniformes civiles y militares, mientras el aire se llenaba de las infinitas melodías de los cantos litúrgicos y de las vibrantes notas de las bandas civiles y castrenses, que los potentes altavoces transmitían; cuando Jesucristo en la Hostia Santa sobre el altar, recibió el enfervorizado homenaje de tantos millares de almas postradas ante la Custodia más rica de Bilbao, trono del Señor, ¿quién no sintió el escalofrío de lo sublime y fue dominado por la más serena, augusta y religiosa emoción ${ }^{57}$
\end{abstract}

La carroza llegó a las siete de la tarde y a su paso la gente se hincaba de rodillas. A la llegada del altar, el Nuncio pasó por debajo de las espadas formadas por los

55. “La jornada triunfal”, La Gaceta del Norte, 23-5-1944.

56. NÚÑEZ, “’La Reconquista de nuestro territorio...””, p. 45-46.

57. Crónica del Congreso Eucarístico de Vizcaya, p. 139. 
bailarines y las bandas de música entonaron otra vez el Himno Nacional, tras lo cual, el Prelado, junto con el representante del Jefe de Estado, subieron el Santísimo al altar. Después de unos cánticos, el Obispo de Vitoria pronunció su discurso, retrasmitido por los altavoces, y tras éste, el Nuncio procedió a la bendición de los asistentes, mientras las seis bandas de música volvieron a tocar el Himno Nacional, y después de unas oraciones, se entonó el Himno Eucarístico con acompañamiento de las bandas.

Imagen 8: Las autoridades arrodilladas en el Arenal en el momento de la bendición

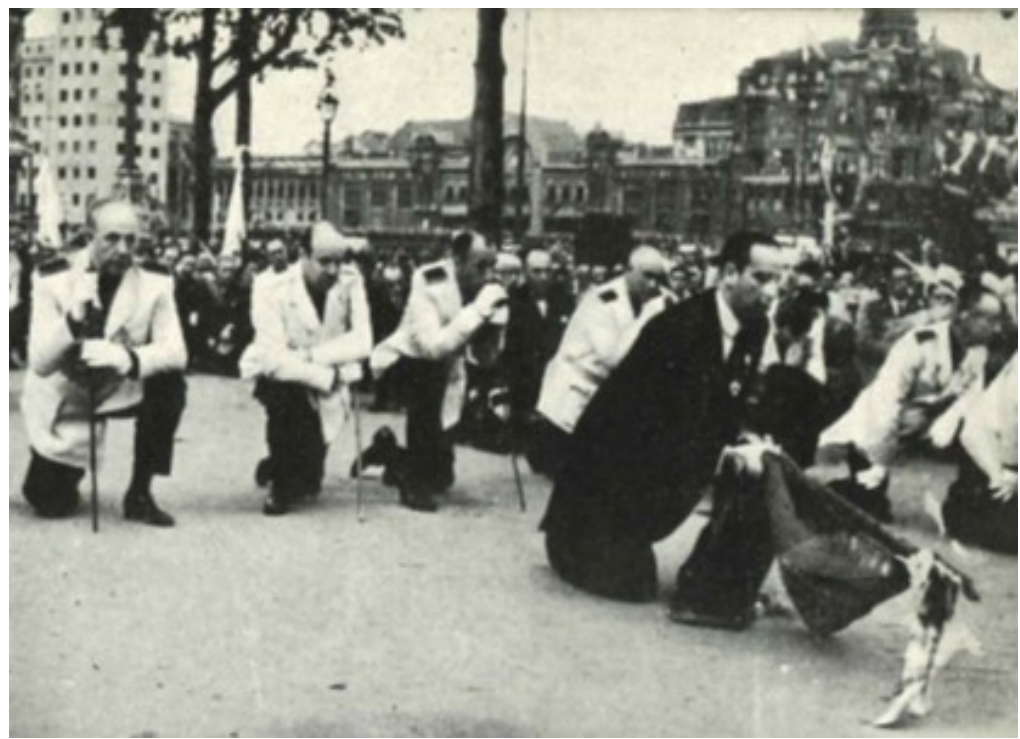

F.: "El Ayuntamiento de Bilbao, en Corporación, durante la bendición con el Santísimo desde el altar del Arenal”, Crónica del Congreso Eucarístico, p. 143.

Con el traslado de la figura a la Iglesia de San Nicolás, se dio por terminado el ritual y el primer Congreso Eucarístico de Vizcaya. Después, todas las autoridades se trasladaron al Palacio Provincial para ver el desfile de las fuerzas militares que habían estado presentes en la procesión.

Imagen 9: Un momento del desfile militar

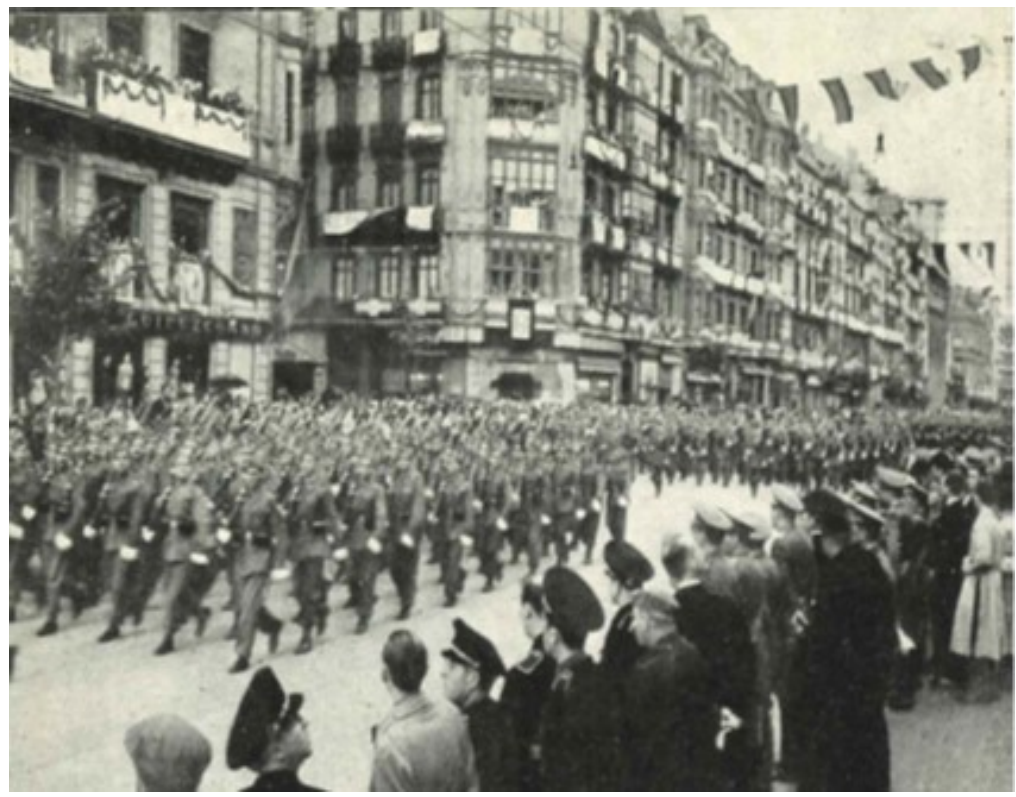

F.: "El desfile marcial, gallardo y animoso de las fuerzas de Infantería después de la Procesión”, Crónica del Congreso Eucarístico, p. 144. 


\section{Conclusiones}

En este artículo hemos partido de la narración de los rituales colectivos que tuvieron lugar en el espacio público en el primer Congreso Eucarístico de Bilbao en el año 1944. El objetivo ha sido ver cómo la Iglesia Católica utilizaba conscientemente recursos sensoriales, teatrales, musicales y plásticos para producir un efecto emocional con la intención de crear subjetividades que estuvieran acorde con la idea de sociedad que desde el régimen defendían. En el contexto de la posguerra, la represión más brutal seguía aplicándose y ello instauró el miedo a cualquier posibilidad de disidencia pública. Por ello, estos acontecimientos significaban un intento de búsqueda de la legitimidad que para el régimen también era necesaria para mantenerse, y para la que se utilizaron rituales propios de las sociedades de masas.

Son dos los momentos rituales en los que se ha detenido el análisis. Uno de los actos principales del ritual estaba destinado a la ocupación de la calle de los niños y niñas de la provincia con el objetivo de crear en ellos una honda impresión que dejara una huella y determinara la formación de sus subjetividades. Este acto representaba un intento de influir en los que se consideraban el futuro de la nación, creando subjetividades acordes a los valores del régimen para que lo perpetuaran. El otro ritual principal que ocupaba las calles tenía un claro componente de género, ya que eran los hombres los que estaban llamados a participar activamente en un ritual de contenido religioso. En este caso, se buscaba el control social y la conformidad con el régimen mediante la defensa de una masculinidad paternalista y su idea de orden jerárquico y tradicional, que se vinculaba con el carlismo y constituía un recurso interesante para conseguir el apoyo y el orden social en unos momentos en los que la perdurabilidad del régimen podía estar especialmente en cuestión.

Por todo ello, es interesante ahondar en la forma en la que el régimen franquista utilizó estos rituales en la imposición de su proyecto, dado que el análisis detallado del funcionamiento de estos dispositivos emocionales y sensoriales puede aportar nuevas visiones a las dimensiones de control social y legitimidad que operaron en el régimen y que nos ayudan a entender la larga duración de éste. 